\title{
Sistem Informasi Geografis Lokasi Jalur Armada Kebersihan Berbasis Android Dinas Lingkungan Hidup Kota Gorontalo
}

${ }^{1}$ Siti Andini Utiarahman, ${ }^{2}$ Alang, ${ }^{3}$ Yusrianto Malago

1,2,3 Universitas Ichsan Gorontalo, Indonesia

Iandiniutiarahman@gmail.com ;2alang.research@gmail.com; 3 3yusrianto_malago@live.com;

\section{Article Info}

Article history:

Received, 15/11/2021

Revised, 18/11/2021

Accepted, 22/11/2021

\section{Kata Kunci:}

android

armada kebersihan

sampah

SIG

\section{Keywords:}

android

garbage truck fleet

garbagel

GIS

\begin{abstract}
ABSTRAK
Untuk mewujudkan lingkungan yang bersih, tidak terlepas dari partisipasi masyarakat untuk menjaga lingkungan disekitarnya serta adanya peran pemerintah dalam hal ini Dinas Lingkungan Hidup Kota Gorontalo. Namun sering terjadi permasalahan lingkungan seperti adanya penumpukan sampah yang berasal dari masyarakat. Penumpukan sampah terjadi dikarenakan masyarakat sulit mendapatkan informasi mengenai waktu operasi dan letak lokasi jalur layanan armada kebersihan di Kota Gorontalo. Sehingga untuk mencegah penumpukan sampah tersebut, diperlukan sistem informasi yang mudah diakses oleh masyarakat terkait waktu operasi armada kebersihan dan dapat dimanfaatkan untuk pencarian lokasi serta menentukan titik koordinat lokasi jalur layanan armada kebersihan. Oleh karena itu penelitian ini bertujuan merancang sistem informasi geografis lokasi jalur armada kebersihan berbasis android yang mudah diakses oleh masyarakat melalui smartphone. Metode penelitian menggunakan Prototyping, dan pemodelan sistem menggunakan UML (Unified Modelling Language). Hasil penelitian dengan sistem informasi geografis berbasis android ini dapat memudahkan masyarakat dalam mengakses informasi terkait waktu operasi dan lokasi jalur layanan armada kebersihan di Kota Gorontalo secara tepat dan akurat sehingga dapat mencegah terjadinya penumpukan sampah.
\end{abstract}

\section{ABSTRACT}

To create a clean environment, it cannot be separated from the participation of the community to protect the surrounding environment and the role of the government in this case, the Environmental Service in Gorontalo City. However, environmental problems often occur such as the accumulation of garbage from the community. The accumulation of garbage occurs because people find it difficult to get information about operating times and the location of the cleaning fleet service line in Gorontalo City. So that, to prevent the accumulation of garbage, an information system that is easily accessible to the public is needed regarding the operating time of the cleaning fleet and it can be used to search for locations and determine the coordinates of the location of the cleaning fleet service line. Therefore, this research aims to design a geographic information system for the location of an Android-based cleaning fleet that is easily accessible by the public via Smartphone. The research method uses Prototyping, and the system modeling uses UML (Unified Modeling Language). The results of this research with an geographic information system based on android can make it easier for the public to access information related to operating times and the location of the cleaning fleet service line in Gorontalo City precisely and accurately so that, as to prevent the accumulation of garbage.

\section{Penulis Korespondensi:}

Siti Andini Utiarahman,

Program Studi Sistem Informasi,

Universitas Ichsan Gorontalo,

Email: andiniutiarahman@gmail.com 


\section{PENDAHULUAN}

Terealisasinya lingkungan bersih menjadi salah satu faktor penunjang kesehatan setiap mahluk sehingga kebersihan berpengaruh dalam memandang kualitas hidup masyarakat [1]. Untuk itu dalam mewujudkan lingkungan bersih bukan hanya tugas dari pemerintah namun diperlukan dukungan dan peran dari masyarakat untuk mewujudkan tata kelola sampah yang baik (good garbage management) [2], sesuai PERDA Kota Gorontalo Nomor 12 tahun 2017 tentang pengelolaan sampah [3]. Dalam pengelolaan sampah tidak terlepas kaitannya dengan masalah sampah yang dari hari ke hari semakin menumpuk, hal ini disebabkan karena pertambahan penduduk yang semakin meningkat dan disertai juga dengan aktivitas manusia yang semakin berkembang dan pembangunan yang dilakukan juga terus meningkat, sehingga bertambahnya volume sampah dan jenis sampah yang beragam. Hal ini juga terjadi di kota Gorontalo. Oleh karena itu selain dibutuhkan partisipasi dari masyarakat untuk menjaga lingkungan agar tetap bersih, diperlukan juga peran pemerintah dalam hal ini Dinas Lingkungan Hidup.

Dinas Lingkungan Hidup mempunyai fungsi dan perannya khususnya seksi kebersihan dan pengangkutan sampah. Menyusun rencana secara teknis dan berbagai kegiatan dibidang kebersihan serta pengangkutan sampah [4]. Terdapat 243 titik tempat pembuangan sampah sementara di Kota Gorontalo yang setiap harinya mengangkut sampat sesuai dengan rute yang ditentukan. Pengangkutan sampah menggunakan armada kebersihan diantaranya ada 28 unit dump truk, 3 unit armroll, 4 unit pick up mega carry, 2 unit pick up L-300 dan 22 gerobak motor viar. Armada kebersihan ini tentunya memiliki waktu operasi dan beberapa titik lokasi yang menjadi jalur pengangkutan sampah, namun masyarakat tidak mengetahui jadwal dan titik lokasi armada tersebut. Sehingga diperlukan sistem informasi yang mudah diakses oleh masyarakat terkait waktu operasi armada kebersihan dan dapat dimanfaatkan untuk pencarian lokasi serta menentukan titik koordinat lokasi jalur layanan armada kebersihan, yaitu dengan sistem informasi geografis.

SIG (Sistem Informasi Geografis) berupa perangkat keras, perangkat lunak serta aplikasi lainnya. Terkenal secara meluas sebagai alat yang dimanfaatkan untuk mengambil keputusan. Baik pemerintah ataupun swasta membutuhkan informasi berbasis data spasial telah mengetahui dan menggunakan sistem tersebut [5]. Sebagai contoh SIG dimanfaatkan bidang lingkungan hidup. Saat dokumen tentang lingkungan diperlukan, maka data informasi terkait jalur armada kebersihan tersedia.

Oleh karena itu penelitian ini bertujuan untuk merancang sistem informasi geografis berbasis android, yang bisa digunakan dimanapun dan kapanpun masyarakat memerlukannya [6]. Sistem ini dirancang menggunakan bahasa pemrograman Android dan PHP serta MySQL sebagai media penyimpanan data. Dengan memanfaatkan GIS, internet, smartphone (android), GPS dan Google maps guna mengakses informasi [7] jalur armada kebersihan, lokasi tempat pembuangan sampah sementara, informasi lokasi jalur layanan armada kebersihan yang dapat diakses dengan mudah melalui smartphone masyarakat.

Penelitian oleh Alang [8] membuat aplikasi yang memanfaatkan kemampuan google maps dan GPS dikombinasikan ke sebuah program aplikasi berbasis android. Bahasa program android serta PHP berkolaborasi dengan $M y S Q L$ sebagai database. Hasil penelitian memberikan informasi tempat pembuangan sampah terdekat. Penelitian Fadel Mohamad [9], bertujuan agar masyarakat dapat mengetahui adanya sampah yang menumpuk dan belum terangkut oleh petugas serta menganalisis keadala yang dihadapi Dinas Lingkungan Hidup dalam menanggulangi sampah. Sistem yang dibuat dapat menanggulangi sampah yang menumpuk, memonitoring armada kebersihan sekaligus titik pembuangan sampah. Dibuat menggunakan Bahasa program android dan MySQL sebagai database. Penelitian oleh C.H.Chen dkk [10], mengusulkan sistem manajemen armada truk sampah yang mencakup On-Board Unit $(O B U)$ pada truk sampah, Sistem Manajemen Armada (FMS) dan GTA dengan optional mekanisme hemat daya untuk memperbaharui pesan berdasarkan informasi lokasi. $O B U$ dilengkapi dengan modul sistem penentuan posisi global (GPS) dengan modul jaringan selular untuk menyediakan data deteksi kedatangan segera dan mengirim lokasi truk sampah ke FMS melalui GPRS. FMS dapat menggabungkan metode perkiraan waktu kedatangan berdasarkan teknik penambangan data dan analisis lokasi truk sampah untuk memberikan perkiraan kedatangan waktu. Masyarakat kemudian dapat menggunakan GTA melalui perangkat selular untuk meminta lokasi tempat sampah, truk dan perkiraan waktu kedatangannya sebelum mereka membuang sampah.

Penelitian oleh Alang dan Fadel hanya menghasilkan informasi tempat sampah dan titik sampah tanpa menampilkan rute lokasi armada kebersihan. Begitu juga penelitian oleh G.H.Chen dkk menghasilkan infromasi lokasi truk sampah tanpa ada rute jalur dari truk sampah.

\section{METODE PENELITIAN}

\subsection{Motode Analisis Sistem}


Metode penelitian ini menggunakan prototyping model, dimana metode pengembangan perangkat lunak seperti model fisik kerja sistem yang mempunyai fungsi terhadap tahap awal [11]. Prototyping model dapat diilustrasikan seperti gambar 1 dibawah ini :

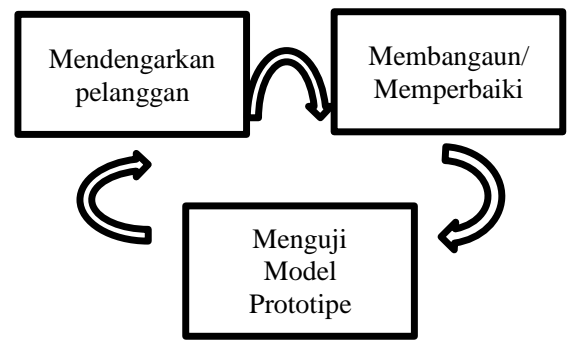

Gambar 1 Ilustrasi Prototyping Model

\subsection{Teknik Pengumpulan Data}

Tahapan penelitian berdasarkan prototyping model dijabarkan seperti berikut ini :

a. Mengumpulkan data dengan cara 1) Observase, melakukan pengamatan langsung dikantor Dinas Lingkungan Hidup, melihat system yang berjalan dan informasi yang dihasilkan. 2) Wawancara, tanya jawab langsung dengan Kepala Dinas Lingkungan Hidup, Kepala Sub Bidang Kebersihan dan Pengangkutan sampah serta staff. 3) Studi Pustaka, Mengumpulkan data pendukung seperti jurnal, buku dan artikel terkait.

b. Membuat UML diantaranya usecase usulan sistem yang dapat dilihat pada gambar 2, penjabaran sequence diagram dari modul login, modul input data armada, modul data TPS, sampai cetak laporan. Begitu juga untuk activity diagram serta class diagram sesuai dengan sequence diagram.

c. Membuat rancangan tampilan antarmuka baik server maupun client berbasis android yang dijabarkan pada gambar 4, 5 dan 6.

d. Menerapkan rancangan serta prototyping yang telah dibuat.

e. Selanjutnya prototyping akan di berikan kepada user untuk melihat feedback. Apabila ada yang perlu di lakukan perbaikan maka prototyping tersebut dilakukan perbaikan sesuai dengan yang dibutuhkan oleh user.

\section{HASIL DAN ANALISIS}

\subsection{Analisis Sistem}

Sistem ini terdapat 2 aktor, yaitu admin dalam hal ini staff Dinas Lingkungan Hidup dan masyarakat sebagai user. Dimulai dengan admin melakukan pengolahan data TPS (Tempat Penampungan Sementara), mengolah data armada kebersihan, mengolah data informasi, mengolah data pengaduan dari masyarakat. Selanjutnya masyarakat menemukan lokasi TPS dan melihat rute yang mengarahkan ke lokasi TPS. Masyarakat dapat melihat lokasi armada kebersihan sekaligus jalur layanan yang dilewati armada kebersihan. Sistem memberikan kemungkinan masyarakat menulis pengaduan serta melihat informasi yang berkaitan dengan Dinas Lingkungan Hidup. Sistem juga dilengkapi dengan fasilitas bantuan disaat masyarakat merasa kesulitan jika aplikasi sulit di gunakan. Untuk lebih jelasnya dapat dibuatkan $U M L$ sebagai alat bantu pendekatan analisis berorientasi objek [12] diantaranya usecase diagram [13]. Gambar 2 berikut ini merupakan use case yang direncanakan: 

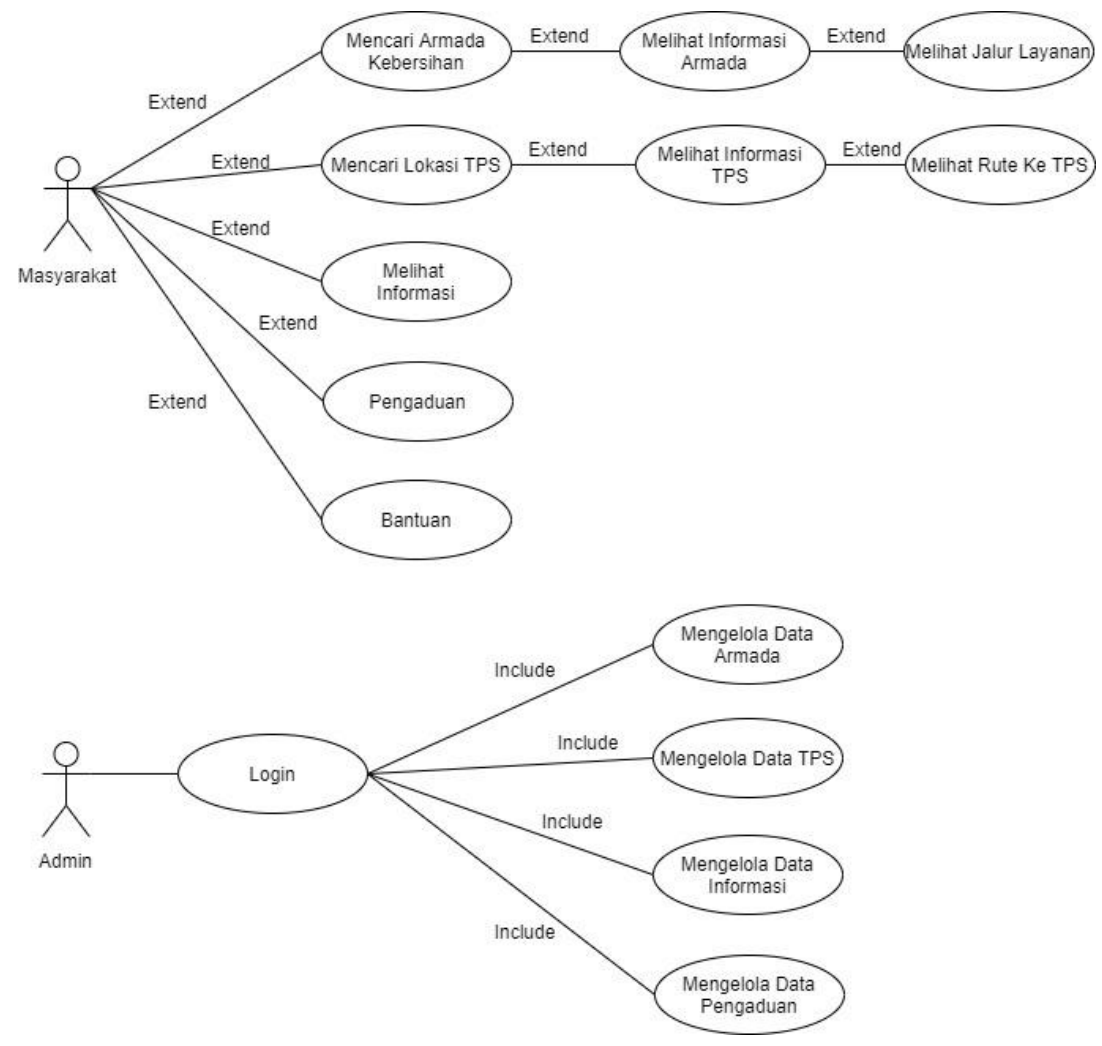

Gambar 2 Use Case yang dirancang

\subsection{Hasil Perancangan Sistem}

Terdiri dari 2 tahapan yaitu merancang database dan merancang antarmuka dijabarkan berikut ini :

a. Merancang database adalah hal utama saat membuat sistem informasi sebab disaat merancang bisa lebih memenuhi baik kebutuhan sekarang atau kebutuhan masa depan [14]. Terdapat 6 tabel yaitu tabel armada kebersihan, tabel TPS, tabel informasi, tabel pengaduan dan tabel admin. Dijabarkan pada gambar 3 berikut ini :



Gambar 3 Rancangan Database

b. Merancang Antarmuka, merupakan rancangan perangkat lunak yang berinteraksi langsung dengan user [15]. Terdapat 2 jenis antarmuka admin dan antarmuka user. 
JSAI : Journal Scientific and Applied Informatics

Vol. 4, No. 3, November 2021, hal. 355 360

E-ISSN: 2614-3054; P-ISSN: 2614-3062, Terakreditasi Kemenristekdikti, Sinta 5

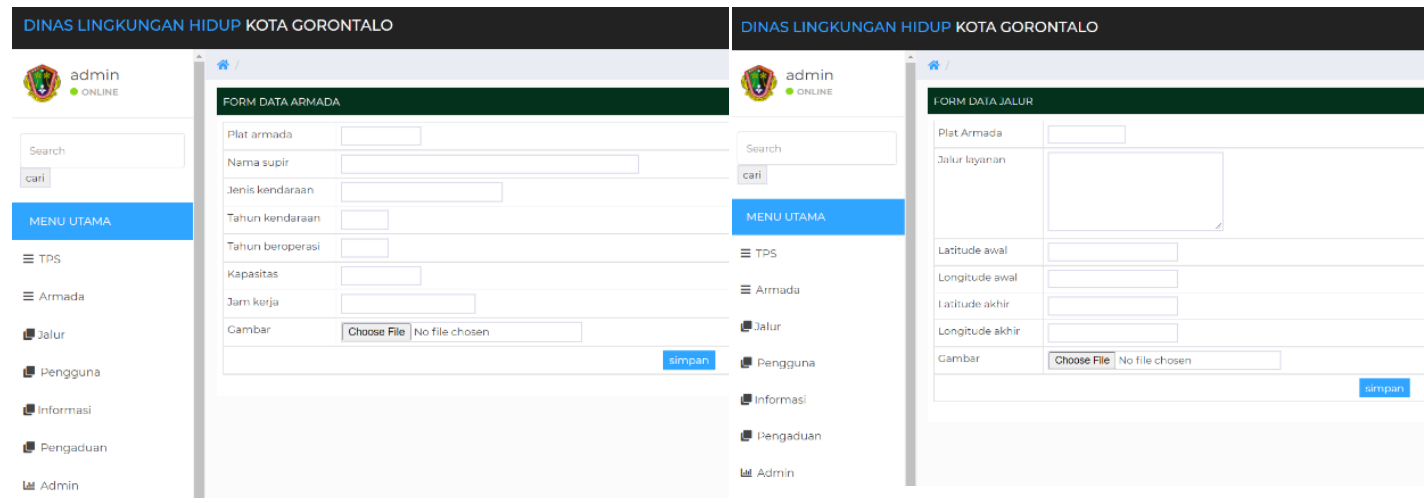

Gambar 4 Antarmuka Data Armada dan Data Jalur

Antarmuka data armada mempunyai fungsi menampilkan apa yang admin input kesistem. Sedangkan Antarmuka data jalur yang mempunyai fungsi menampilkan apa yang admin input kesistem.

b.2 Antarmuka User(masyarakat), terdiri atas 4 tampilan menu, daftar armada, data detail armada kebersihan, data detail TPS.
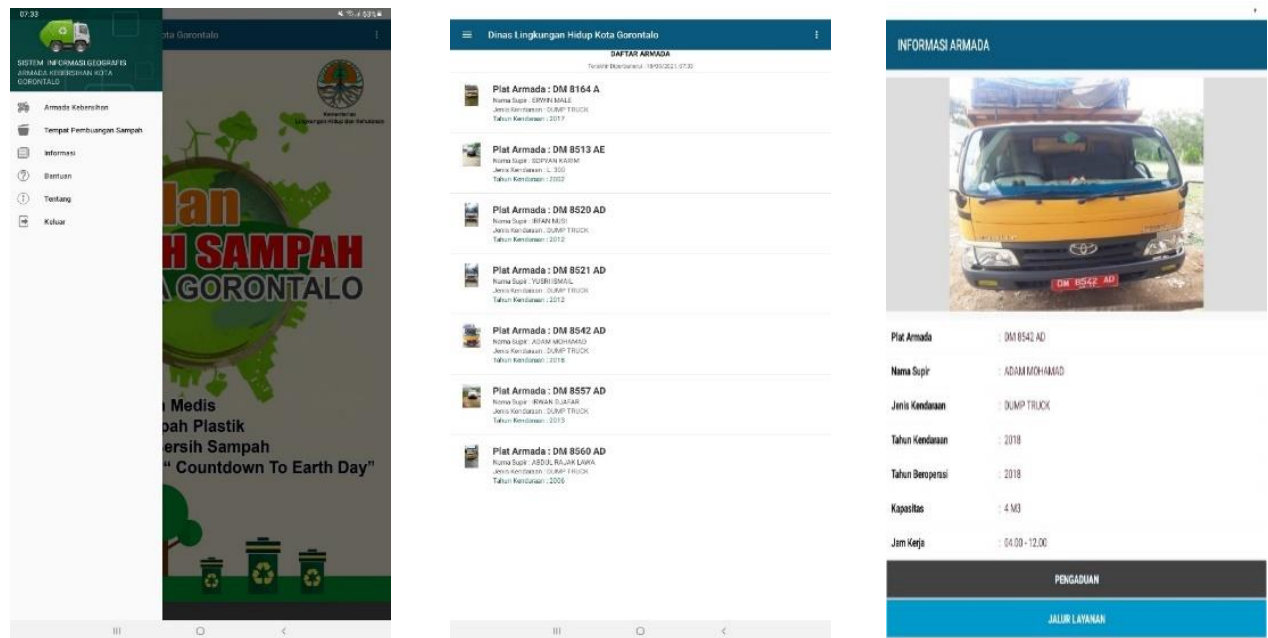

Gambar 5 Antarmuka Menu Utama, Daftar Armada dan Detail Armada Kebersihan
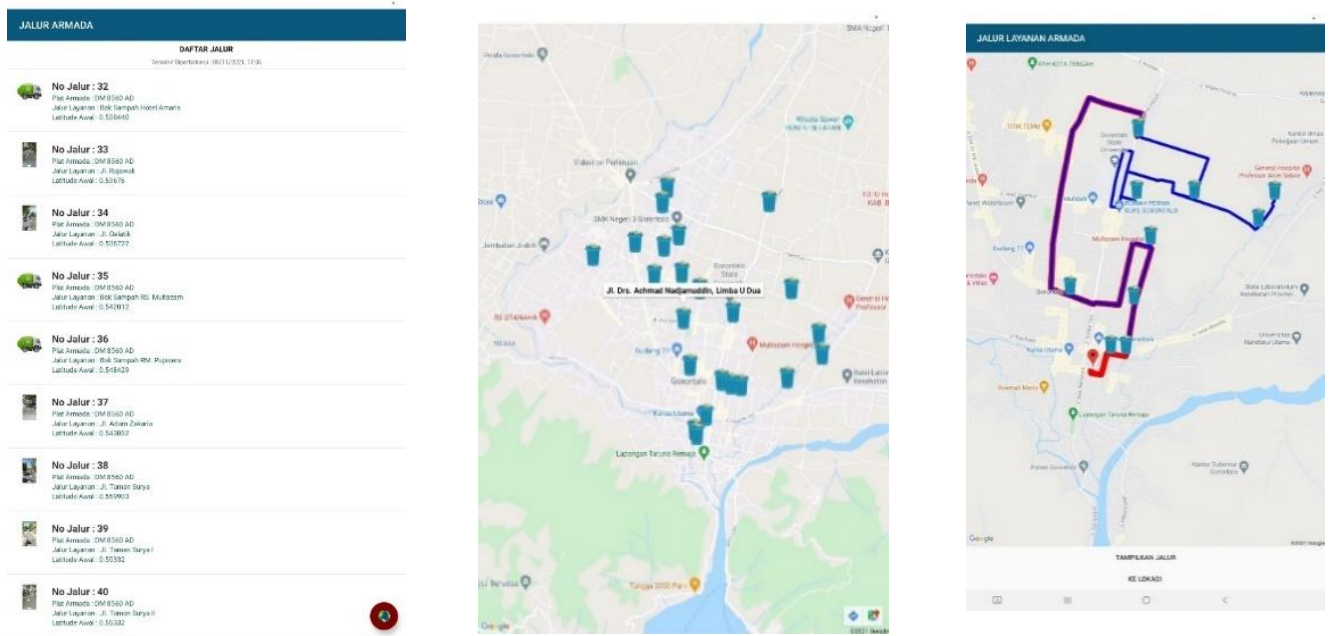

Gambar 6 Antarmuka Daftar Jalur Armada, Lokasi TPS dan Jalur Armada Kebersihan 


\section{KESIMPULAN}

Hasil penelitian dengan sistem informasi geografis berbasis android menggunakan bahasa pemrograman PHP yang digunakan untuk merancang antarmuka pengguna, serta MySQL yang digunakan untuk database, dapat memudahkan masyarakat dalam mengakses informasi terkait waktu operasi dan lokasi jalur layanan armada kebersihan di Kota Gorontalo secara tepat dan akurat sehingga dapat mencegah terjadinya penumpukan sampah serta membantu masyarakat dalam memberikan pengaduan terkait masalah sampah.

\section{REFERENSI}

[1] K. G. Sine, “Terhadap Kebersihan Lingkungan Sekitarnya,” vol. 2020, pp. 60-65, 2020.

[2] Maria permata agustini, “ Implementasi Good Governance Dalam Pengelolaan Sampah ,” Kaji. Apar. PKP2A III LAN Samarinda, vol. 2, no. 2, pp. 114-127, 2009.

[3] P. K. Gorontalo, "Pengelolaan Sampah," Gorontalo, 2017.

[4] P. W. Gorontalo, "Peraturan Walikota Gorontalo tentang Kedudukan, Susunan Organisasi, Tugas dan Fungsi serta Tata Kerja Dinas Lingkungan Hidup Kota Gorontalo," 2016.

[5] M. S. Ahmat Adil., S.Kom., Sistem Informasi Geografis, 1st ed. Yogyakarta: Andi Offset, 2017.

[6] A. Ismawari, B. Sitepu ${ }^{1}$, D. Yani, and H. Tanjung ${ }^{2}$, "Rancang Bangun Aplikasi Pemesanan dan Penjualan Berbasis Web dan Android pada Toko YT. Wall Interior," J. FTIK, vol. 1, no. 1, pp. 816828,2020

[7] M. Yanto, "Sistem Informasi Geografis Lokasi Perkebunan Disepanjang Garis Pantai Pesisir Selatan Berbasis Android," J. Ilm. Media Sisfo, vol. 13, no. 1, p. 28, 2019, doi: 10.33998/mediasisfo.2019.13.1.586.

[8] F. Teknik and U. Negeri, "Kota Gorontalo),” vol. 8, no. September 2011, pp. 102-117, 2021.

[9] F. Mohamad, F. Tupamahu, and L. B. Masalah, "Rancangan Sistem Integrasi Monitoring Dan Pelaporan Sampah," Semin. Nas. Teknol. Sains dan Hum. 2019, vol. 2019, no. November, pp. 50-57, 2019.

[10] C. H. Chen, Y. T. Yang, C. S. Chang, C. M. Hsieh, T. S. Kuan, and K. R. Lo, "The design and implementation of a garbage truck fleet management system," South African J. Ind. Eng., vol. 27, no. 1, pp. 32-46, 2016, doi: 10.7166/27-1-982.

[11] D. Purnomo, "Model Prototyping Pada Pengembangan Sistem Informasi," J I M P - J. Inform. Merdeka Pasuruan, vol. 2, no. 2, pp. 54-61, 2017, doi: 10.37438/jimp.v2i2.67.

[12] S. A. Utiarahman and S. D. Ali, "Sistem Informasi Geografis Potensi Sumber Daya Alam di Wilayah Kabupaten Banggai Kepulauan Berbasis Android," J. Inform. Upgris, vol. 6, no. 1, 2020, doi: 10.26877/jiu.v6i1.5221.

[13] S. A. Utiarahman, N. O. Idris, and N. O. Idris, "Sistem Informasi Geografis Lokasi Usaha Servis Komputer dan Laptop di Kota Gorontalo Berbasis Android," J. Inform. Upgris, vol. 7, no. 1, 2021, doi: $10.26877 /$ jiu.v7i1.8310.

[14] R. Umar, A. Hadi, P. Widiandana, and F. Anwar, "Perancangan Database Point of Sales Apotek Dengan Menerapkan Model Data Relasional," Query J. Inf. Syst., vol. 5341, no. October, pp. 33-41, 2019.

[15] F. S. Nugraha, F. H. Purwanto, . M., M. Huda, M. Munir, and R. T. Puji, "Perancangan Antarmuka Sistem Pakar Penyakit Padi Berbasis Web," Sisfotenika, vol. 7, no. 2, p. 143, 2017, doi: 10.30700/jst.v7i2.154. 